How to cite this article:

Ajoge, N. S., Aziz, A. A., \& Mohd Yusof, S. A. (2020). A computational model of temporal dynamics for anxiety in interviewee mental state. Journal of Information and Communication Technology, 19(2), 185-206. https://doi.org/10.32890/jict2020.19.2.2

\title{
A COMPUTATIONAL MODEL OF TEMPORAL DYNAMICS FOR ANXIETY IN INTERVIEWEE MENTAL STATE
}

${ }^{1}$ Naseer Sanni Ajoge, ${ }^{2}$ Azizi Ab Aziz \& ${ }^{2}$ Shahrul Azmi Mohd Yusof

${ }^{I}$ Department of Computer Science, Kaduna Polytechnic, Nigeria

${ }^{2}$ School of Computing, Universiti Utara Malaysia, Malaysia

ajogenass@yahoo.com; aziziaziz,shahrulazmi@uum.edu.my

\begin{abstract}
Anxiety is an aversive motivational state that occurs when an individual perceives threat at events. This condition creates harmful effects for candidates during interview sessions. An interviewee overwhelmed in such a state deploys worry as a resource to cope with the threat hence losing the ability to present the self positively for favourable assessments. Most of the digital approaches to assist interviewees in this condition are focused on coaching of verbal and non-verbal cues. The aspect of understanding interviewees' psychological complexities that influence their behavioural tendencies is lacking in these approaches. As the first step in building an intelligent digital based therapy platform to overcome this issue, this article provides a building block to understanding the interviewees' anxiety state by means of a computational model. This model is developed based on the conceptual model derived from generalized anxiety disorder theories. The formal model is evaluated using mathematical analysis to determine possible equilibria state and the simulation results are tested against known cases in the literature. The simulation results showed that the degree of threats perceived at events is based on task demands and the resources to cope. Threat is the building block of anxiety through worry which is controlled by one's personality and inherent
\end{abstract}


trait anxiety. The results conform to established facts in the literature. Consequently, this model can serve as a basis to build an integrated interviewee mental state model embedded with self-efficacy and motivation constructs as a holistic approach to support interviewees in coaching environments during simulated training.

Keywords: Anxiety states, computational cognitive modeling, intelligent support agent, interviewee behavioural states

\section{INTRODUCTION}

During interviewing processes, candidates are expected to be calm, diligent and capable of maintaining their composure throughout the duration. These abilities have been identified as the most important steps prior to being selected for the next round of interview or full employment (Feiler \& Powell, 2015; McCarthy \& Goffin, 2004; Scivicque, 2013). Therefore, the significance of interview performance in hiring processes has prompted researchers to determine the most related aspects that contribute towards employment selection decisions (Feiler \& Powell, 2015; Huffcutt, Van Iddekinge, \& Roth, 2011). Although specific behavioural skills, such as appropriateness of speech content, verbal fluency, and composure of interviewees are related to effective interview results, cognitive factors such as worry or anxiety also play important roles. During interviews, it is possible to invoke personal anxiety and as a consequence, inhibit effective performance during the interview (Heimberg \& Keller, 1986; Huffcutt et al., 2011). Moreover, it is common to view an anxiety state as an aversive motivational state that occurs when any condition is perceived as a threatening case and it is consistent across many interviewing processes (Derakshan \& Eysenck, 2009; McCarthy \& Goffin, 2004). Without control, a prospective interviewee will be most affected by this pervasive problem, as the competitive and evaluative nature of the selection process is capable of evoking frustration and distress (Rynes, Bretz, \& Gerhart, 1991). In addition, a number of findings have proved that interviews involve social dialogue between the candidates (interviewees) and an unknown personality(s) (interviewer or interviewers), and in such conditions interviewees with relatively low control can trigger anxiety (Ayres, Keereetaweep, Chen, \& Edwards, 1998). Therefore, it can be generalized that the anxiety state can be considered as a fundamental factor in any interviewing and selection processes as it is highly evaluative and demanding in nature (Kwon, Powell, \& Chalmers, 2013; McCarthy \& Goffin, 2004).

Thus, several support programmes have been designed to overcome anxiety and non-assertive behaviours from a cognitive-behavioural perspective 
(Cuncic, 2018; Gong, Wen, Dajun, \& Delef, 2016; Heimberg, Madsen, Montgomery, \& Mcnabb, 1980). Another alternative is to provide a digital solution by harnessing a cognitive agent paradigm in designing intelligent artefact that provides smart support for the interviewee. To date, intelligent interview coaching systems have been developed to serve these purposes through recognising users based on verbal and non-verbal gestures that are measurable during interviews e.g. MACH (Hoque, Matthieu, \& Martin, 2013); and TARDIS (Anderson et al., 2013).

However, the aspect of human-aware AI approach for reasoning and understanding human dynamism which affects human behaviour is still a critical challenge to be explored in order to enhance the different digital systems highlighted earlier (Mohan, Venkatakrishnan, Bobrow, \& Pirolli, 2017). An AI system must include aspects of intelligence, such as emotional, cognitive or social so that it can be more adaptive and work in synergy with humans. AI technologies are being considered for implementation in several domains of human endeavour as a result of the robustness in AI algorithms and research (Mohan et al., 2017). Designing such human-aware systems for the domain of interest involves modeling human mental states in order to identify desires and intentions (Bosse, Memon, \& Treur, 2011; Narayanan, Zhang, \& Kambhampati, 2015; Nunes \& Luck, 2014), provide proactive support (Chakraborti, Zhang, Smith, \& Kambhampati, 2016; Zakershahrak, Sonawane, Gong, \& Zhang, 2018), reveal rational behaviour (Fernandes, Custodio, Alves, \& Fisher, 2017), and provide logical justifications and develop trust (Khalid, Wei Shiung, Bin Sheng, \& Helander, 2018) based on changes in human physiological, cognitive and affective states.

As a first step in developing such a system, interview anxiety which is key in cognitive processes during interview sessions needs to be formally analysed and incorporated with other important constructs. For example, the three major constructs that have been hypothesised to define the influence of interviewee states are anxiety, self-efficacy and motivation (Huffcutt et al., 2011). These three constructs are fundamentally different but are internally related to the interplaying factors (Piniel \& Csizer, 2015). Harnessing the interplaying factors in order to integrate the constructs is an important aspect to identifying the mental framework (Piniel \& Csizer, 2015; Piniel \& Csizér, 2013) in human cognition that can be related to the influence of interviewee states (Huffcutt et al., 2011). The anxiety construct measures the stability of the interviewee in terms of fright, while self-efficacy measures beliefs in personal competence and motivation drives an internal inspiration to perform well during the interviewing process (Schunk, 1995; Tahmassian \& Moghadam, 2011).

Anxiety has been studied from several fronts especially to identify its effects on human behavioural intricacies, for example, in Berenbaum (2010), 
Derakshan and Eysenck (2009), Eysenck and Calvo (1992), and Schwartz (2018). In the interview domain, the relationship between interviewee anxiety and interview performance have been studied (Feiler \& Powell, 2015; Jeske, Shultz, \& Owen, 2018; McCarthy \& Goffin, 2004). The consensus is that anxiety negatively affects interview performance. However, the approach to computationally model the intricacies of anxiety that is capable of manoeuvring human state in critical activities such as job interviews have not gained much research attention. The study by Aziz, Ahmad, Yusof, Ahmad, and Yusof (2016) was an effort to formally analyse anxiety states and traits for virtual patients. The model was built based on the theory of generalized anxiety disorder with particular sentiment towards anxiety on a long term as an inroad to depression. The study conceptualized worry from short-term response to the event and coping strategy(s) without the inclusion of threat as a building mechanics of affective states. However, an anxiety model that is geared towards understanding the mental states of interviewees requires cognitive (defined by self-efficacy) and motivational factors to be reflected (Piniel \& Csizér, 2013). As a consequence, this article presents a computational model of the temporal dynamics of interviewee anxiety derived from selected grounded theories as an extension of the model in Aziz et al. (2016). Hence, the extended model can be incorporated with interviewee self-efficacy, and interview motivation constructs to form an integrated cognitive model for interviewee mental states (Ajoge, Aziz, \& Mohd Yusof, 2017). This integrated model will serve as a basis in designing an intelligent coaching agent that provides support in a simulated interview environment.

This article is segmented into four parts. Section One introduces the motivation of the study and Section Two looks at the theories and underlying concepts in anxiety. The formalization process of the model is discussed in Section Three while Section Four covers the verification part. Finally, Section Five concludes the article.

\section{UNDERLYING CONCEPTS IN INTERVIEW ANXIETY}

The dynamics behind experienced anxiety is complex and can be defined in the dimensions of behavioural, cognitive, emotional or physical symptoms (Matthew, Melanie, Sony, \& Fugen, 2017). There are two parts in anxiety, namely traits and states. A trait is related to the individual's vulnerability towards anxiety based on personality, while the state is the reaction to threatening situations that are normally associated with stress and physiological responses (e.g. increased heart rate). This condition is imperative towards success in critical activities such as job interviews (Feiler \& Powell, 2015). Contrary to traits, state anxiety is generally short-lived as it is only triggered by immediate threatening events (Eysenck \& Calvo, 1992). Without control, anxiety may 
inhibit performance especially on tasks with high attention or short-term memory demands (Eysenck \& Calvo, 1992).

In the real world, anxiety may impair an individual's performance by worrying about a possible threat. This forces such a person to adopt different coping strategies which invariably takes attention away from the main problem (Wells, 1999). According to Processing Efficiency Theory, experienced worry has two main effects; (1) a decrease in the capacity of working memory required for storage and processing concurrent tasks; and (2) an increment in the on-task effort and activities designed to improve performance (Eysenck \& Calvo, 1992). The postulations from these studies allude to the fact that a viable anxiety model for a demanding task like interviewing for job selection involves the definition of causal factors that inhibits performance (Feiler \& Powell, 2015).

Theories of test-taking anxiety are relevant to interview anxiety since both tests and selection interviews have selective and strict evaluative tendencies (McCarthy \& Goffin, 2004). The numerous studies and theories on test-taking anxiety have simple convergence in the categorization of this type of anxiety into either being "performance anxiety" (i.e. worry) or "behavioural anxiety" (i.e. emotion). Performance anxiety is the concern or worry over the outcome of a test and can be conceptualized as "fear of failure in a test." However, behavioural anxiety reflects experienced autonomic arousal that can be conceptualized as bodily tension during test-taking events (Spielberger \& Vagg, 1995). Thus, in order to develop a conceptual model of interview anxiety, important causal factors of Type I Worry from assertiveness and trait factors that inhibit thought processes during the interview are required. From this spectrum, an interview anxiety condition is related to negative emotion as a consequence of the constant experienced worry. This type of worry is constructed based on the negative belief about worry and danger visualization (self-appraisal) that has been perceived as a threat either before or during the interview session.

Generally, experienced worry takes place when an individual perceives the prospect of a potential threat (Borkovec, Alcaine, \& Behar, 2004; Tallis, Eysenck, \& Mathews, 1991). Hence, when the perceived threat is high, it increases the severity of the experienced worry. In this model, the perceived threat that has been presented was derived from insights in a mental state which an individual perceives himself/herself unable to cope with the assigned task(s) (Fonseca, Blascovich, \& Garcia-Marques, 2014). This concept begins with the activation of threat and subsequent biological, emotional, behavioural and cognitive responses that result from relative evaluations in coping resources (e.g., social support, autonomy, competence beliefs, skills, and previous knowledge) and task demands (e.g., required effort, danger, task difficulty, uncertainty, perceived relatedness). In this manner, threat ensues where an individual implicitly or explicitly evaluates fewer resources to cope with 
existing situation demands to solve the assigned task(s) (Fonseca et al., 2014). In this context, personal competence is the belief one has in his/her ability to organize a course of action required to manage a prospective situation, conceptualized as self-efficacy belief, which contributes positively to reducing the feel of threat of the event (Tan-Kristanto \& Kiropoulos, 2015).

Furthermore, the unpleasant thoughts that arise from a threatening situation triggers worry as a basic coping response (Berenbaum, 2010). In this case, the Type 1 Worry is maintained by metacognitive beliefs concerning the benefits and dangers of worrying (Wells, 1999, 2005). Taking into a positive aspect, the belief about worry is a normal feeling about using worry as a coping strategy to an experienced event. Contrary to this is a negative metacognitive belief about worry which further escalates the individual's worry into Type 2 or meta-worry. As a result, it invokes the anxiety state and may reinforce negative beliefs about worry (Ellis \& Hudson, 2010; Wells, 1999).

Thus, by applying similar concepts in an interview session that involves social interaction with unfamiliar personality, it shows that an individual with a high anxiety trait tends to direct his/her attention towards potentially negative outcomes (Hirsch \& Mathews, 2012; Hayes, Hirsch, Krebs, \& Mathews, 2010). Also, the high level of anxiety and worry are characterized by selective attention to the threatening signs corresponding to human body sensations, mental images or worrisome thoughts (Hayes et al., 2010). As genetic predisposition factors and experiences can interact in the acquisition of emotional processing biases they also relate to the personality factor and traits in defining the sensitivity of an individual (Hirsch \& Mathews, 2012). The initiation of this condition will affect an individual's interpretation and adaptive tendencies when dealing with social assessment conditions like interviewing processes. Assertiveness is a component of the personality factor that is also an important consideration in the model of interview anxiety. The thought processes of non-assertive persons is an "internal dialogue of conflict" which relates to thoughts about one's inadequately answering questions or about the possibility of negative evaluation by the interviewer (Forbes, 2011).

Summarily, anxiety during the interview situation can be caused by a series of psychological and physiological factors (Soeter \& Kindt, 2015). Leading to anxiety is worry on a long term which manifests due to low coping resources to withstand perceived threats (Ellis \& Hudson, 2010; Gong, Wen, Dajun, \& Delef, 2016; Hirsch \& Mathews, 2012). Coping resources is an internal factor that is developed by the strength of belief in one's own abilities (self-efficacy), experience in similar tasks and social support (Levy, Nicholls, \& Polman, 2011; Wells, 1999). However, good coping resources and low situation demands reduce perceived threats (Tan-Kristanto \& Kiropoulos, 2015). High trait anxiety with negative personality influences belief about worry through sensitivity which also has a negative effect on appraisal (Wells, 1999). Belief about worry influences more resources to be channelled to 
cope with the worry hence more worry, and prolonged short-term worry will increase the risk of long-term worry in the future (Barrows, Dunn, \& Lloyd, 2013).

The relevant factors relating to interview anxiety model are described in Table 1 below.

Table 1

Identified Interview Anxiety Factors

\begin{tabular}{|c|c|c|c|c|c|}
\hline & SN & Concept & Notation & Description & Reference \\
\hline \multirow{9}{*}{ 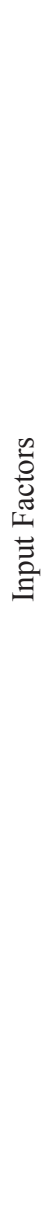 } & 1 & $\begin{array}{l}\text { Perceived } \\
\text { Relatedness }\end{array}$ & $R d$ & $\begin{array}{l}\text { The feeling of } \\
\text { connectedness with } \\
\text { the interviewer }\end{array}$ & (Fonseca et al., 2014) \\
\hline & 2 & $\begin{array}{l}\text { Perceived Task } \\
\text { Difficulty }\end{array}$ & $P d$ & Task complexity & (Fonseca et al., 2014) \\
\hline & 3 & Self-Efficacy & $S f$ & $\begin{array}{l}\text { Belief in one's ability } \\
\text { to engage in a course } \\
\text { of action necessary } \\
\text { to solve a specific } \\
\text { task }\end{array}$ & (Barrows et al., 2013) \\
\hline & 4 & $\begin{array}{l}\text { Prior } \\
\text { Experience }\end{array}$ & $\mathrm{Pe}$ & $\begin{array}{l}\text { Positive engagements } \\
\text { in an interview or } \\
\text { related task }\end{array}$ & $\begin{array}{l}\text { (Ekambareshwar et al., } \\
\text { 2018; Fonseca et al., } \\
\text { 2014) }\end{array}$ \\
\hline & 5 & $\begin{array}{l}\text { Personal } \\
\text { Autonomy }\end{array}$ & $P a$ & Freedom of action & (Fonseca et al., 2014) \\
\hline & 6 & Social Support & Ss & $\begin{array}{l}\text { Support from close } \\
\text { associates }\end{array}$ & (Schunk, 1995) \\
\hline & 7 & Trait (anxiety) & $\operatorname{Tr}$ & $\begin{array}{l}\text { The inherent feeling } \\
\text { of anxiety }\end{array}$ & (Feiler \& Powell, 2015) \\
\hline & 8 & $\begin{array}{l}\text { Personality } \\
\text { (assertiveness) }\end{array}$ & $P n$ & $\begin{array}{l}\text { Quality of being self- } \\
\text { assured and confident } \\
\text { without being } \\
\text { aggressive }\end{array}$ & $\begin{array}{l}\text { (Lounsbury et al., } \\
\text { 2003) }\end{array}$ \\
\hline & 9 & $\begin{array}{l}\text { Situation } \\
\text { Demand }\end{array}$ & $S d$ & $\begin{array}{l}\text { Perceived interview } \\
\text { situation complexity } \\
\text { in relation to } \\
\text { difficulty and } \\
\text { relatedness }\end{array}$ & $\begin{array}{l}\text { (Bakker \& Demerouti, } \\
\text { 2017) }\end{array}$ \\
\hline
\end{tabular}




\begin{tabular}{|c|c|c|c|c|c|}
\hline & SN & Concept & Notation & Description & Reference \\
\hline \multirow{7}{*}{ 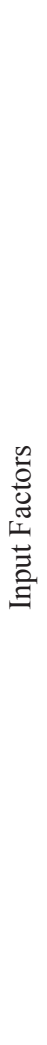 } & 10 & $\begin{array}{l}\text { Perceived } \\
\text { Threat }\end{array}$ & $T h$ & $\begin{array}{l}\text { Evaluation of } \\
\text { lesser resources to } \\
\text { cope with situation } \\
\text { demands of a task }\end{array}$ & (Fonseca et al., 2014) \\
\hline & 11 & $\begin{array}{l}\text { Coping } \\
\text { Resources }\end{array}$ & $\mathrm{Cr}$ & $\begin{array}{l}\text { Human resources } \\
\text { needed to meet } \\
\text { situation demands }\end{array}$ & (Fonseca et al., 2014) \\
\hline & 12 & Sensitivity & Sy & $\begin{array}{l}\text { Degree of awareness } \\
\text { and responsiveness to } \\
\text { internal and external } \\
\text { challenges, or } \\
\text { demands }\end{array}$ & $\begin{array}{l}\text { (MacDorman \& } \\
\text { Entezari, 2015) }\end{array}$ \\
\hline & 13 & $\begin{array}{l}\text { Belief about } \\
\text { Worry }\end{array}$ & $B w$ & $\begin{array}{l}\text { Worry as a coping } \\
\text { strategy in a } \\
\text { threatening situation }\end{array}$ & $\begin{array}{l}\text { (Barrows et al., 2013; } \\
\text { Ryum et al., 2017) }\end{array}$ \\
\hline & 14 & $\begin{array}{l}\text { Experience } \\
\text { worry (Short- } \\
\text { term and } \\
\text { Long-term) }\end{array}$ & $\begin{array}{c}\text { Sw and } \\
L w\end{array}$ & $\begin{array}{l}\text { The state of being } \\
\text { anxious and troubled }\end{array}$ & $\begin{array}{l}\text { (Gong et al., 2016; } \\
\text { Ryum et al., 2017) }\end{array}$ \\
\hline & 15 & Appraisal & $A p$ & $\begin{array}{l}\text { Evaluation of one's } \\
\text { reaction to worry }\end{array}$ & (Wells, 1999) \\
\hline & 16 & $\begin{array}{l}\text { Thought } \\
\text { control }\end{array}$ & $T c$ & $\begin{array}{l}\text { Ability to manage } \\
\text { beliefs in a } \\
\text { threatening situation }\end{array}$ & (Ryum et al., 2017) \\
\hline
\end{tabular}

\section{FORMALIZATION OF AN INTERVIEW ANXIETY MODEL}

This section discusses the details of the dynamic model. The characteristics of the proposed model are tailored to the researches discussed in the previous section on theories and concepts linked to interviewee anxiety.

\section{Conceptual Model of Interviewee Anxiety}

The structural relationships in the model have been determined from the derived concepts presented in Table 1. Figure 1 shows an overview of the states and relationships. The arrow between states define causal influences. Input (exogenous) factors initiate action by sending signals. Internal (endogenous) factors receive and may also send signals. The internal factors are categorized into either with immediate actions (instantaneous) or state with accumulative effects of time (temporal). All grey coloured oval shapes represent temporal 
factors in this model. Some input factors are considered composite because they represent other concepts that are not necessarily presented in this model. Such factors are designated with framed oval shapes. For example, perceived task difficulty and self-efficacy have been represented in previous models of motivation (Ajoge, Aziz, et al., 2017) and self-efficacy (Ajoge, Aziz, \& Mohd Yusof, 2017) respectively causally defined by other concepts.

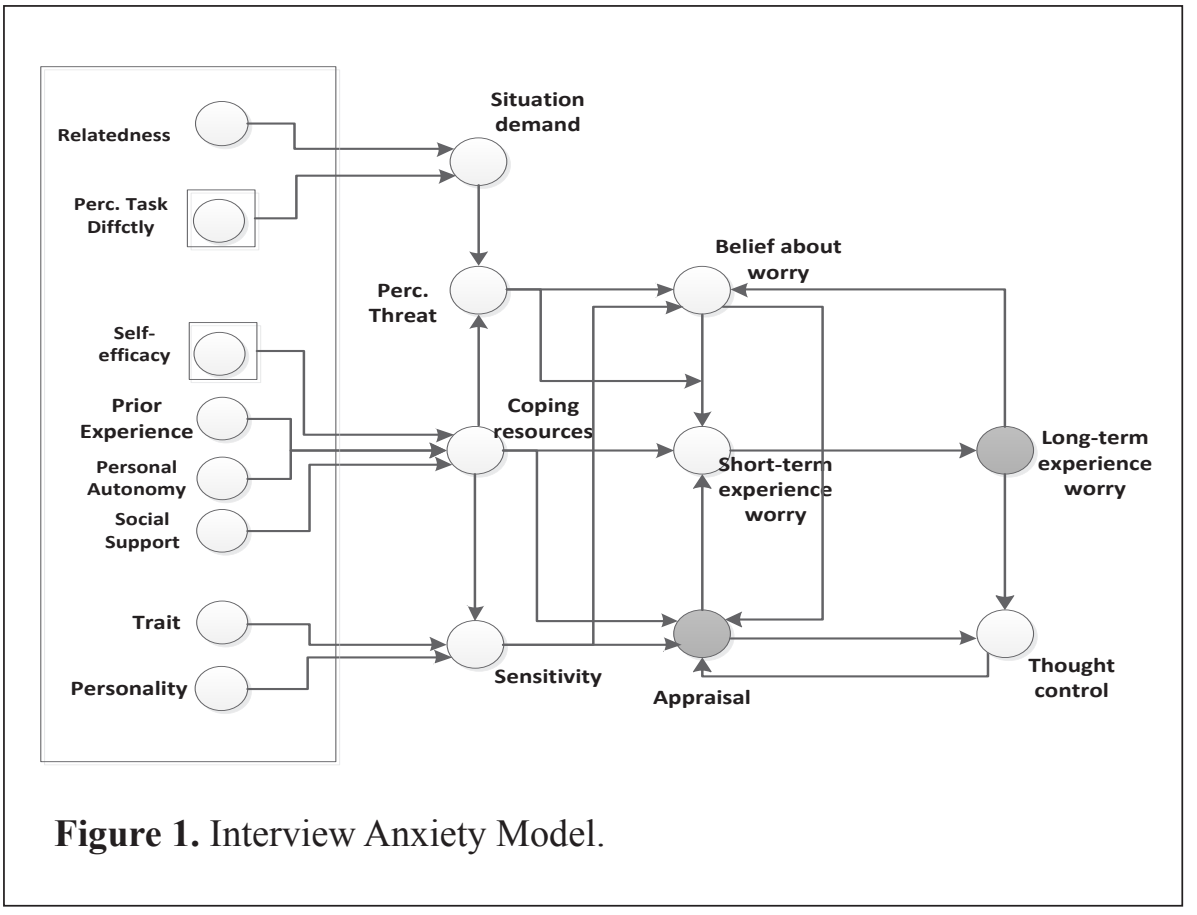

\section{Formalization}

In formalizing the model, instantaneous factors are mathematically formulated according to causal impacts of relating concepts in Figure 1.

\section{Relationship of Threat and Sensitivity States to Coping Resources and Situation Demands}

The feeling of threat is the foundation of worry in evaluating situations such as an interview. The interviewee can be worried when they feel they have less internal resources such as skills, experience or knowledge to withstand the prevailing situation demands. Therefore, threat $(T h)$ ensues when there are inadequate coping resources $(\mathrm{Cr})$ to withstand situation demands $(\mathrm{Sd})$ (Fonseca et al., 2014). Situation demands $(S d)$ are various environmental 
factors which an interviewee has to manage (Bakker \& Demerouti, 2017). This can be viewed in an interview situation from the concept of perceived task difficulty $(P d)$ and perceived relatedness $(R d)$. First, the perceived task difficulty is a composite factor that increases situation demands but the effect of perceived relatedness (i.e. from the interviewer disposition) reduces the formation of the situation demands state. On the other hand, coping resources $(\mathrm{Cr})$ is a state defined by interactions with the external social environment and personal factors such as experience in similar tasks $(P e)$, social support $(S s)$, self-efficacy $(L f)$ and degree of the feeling of freedom (personal autonomy) $(P a)$ (Fonseca et al., 2014). Sensitivity $(S y)$ is defined by the inherent trait $(T r)$ of an individual as well as his/her personality $(P n)$. Assertiveness is a personality feature that defines one's stability level. A highly assertive personality is less sensitive to arousal or anxious moments (Feiler \& Powell, 2015; Lounsbury et al., 2003). High sensitivity is related to genetic disposition (traits and personality) and can be stabilized by the level of coping resources (Cr) (MacDorman \& Entezari, 2015).

From Equations 1 to 4 , Situation demands $(S d)$ is causally constituted in interview situations by perceived task difficulty $(T d)$ and interviewer disposition which are conceptualized as interviewee perceived relatedness $(R d)$. Coping resources $(\mathrm{Cr})$ is conceptualized from available human resources to withstand uncertainties and perceived dangers during interview sessions. The higher the prior experience $(\mathrm{Pe})$ acquired at similar events and perceived social support $(\mathrm{Ss})$, the higher the coping resources $(\mathrm{Cr})$. Perceived competence conceptualized as self-efficacy $(\mathrm{Se})$ and perceived freedom of choice conceptualized as personal autonomy $(\mathrm{Pa})$ both contribute positively to coping resources. The feeling of Threat $(T h)$ is increased by highly unfavourable situation demands $(\mathrm{Sd})$ and reduced by high-level coping resources $(\mathrm{Cr})$.

$$
\begin{aligned}
& S d(t)=\operatorname{Td}(t) \cdot(1-R d(t)) \\
& \operatorname{Cr}(t)=\omega_{c r 1} \cdot \operatorname{Pe}(t)+\omega_{c r 2} \cdot S s(t)+\omega_{c r 3} \cdot S e(t)+\omega_{c r 4} \cdot \operatorname{Pa}(t) \\
& \operatorname{Th}(t)=\operatorname{Sd}(t) \cdot(1-\operatorname{Cr}(t)) \\
& S y(t)=\operatorname{Tr}(t) \cdot\left(1-\left(\alpha_{s y} \cdot(\operatorname{Pn}(t))+\left(1-\alpha_{s y}\right) \cdot \operatorname{Cr}(t)\right)\right)
\end{aligned}
$$

\section{Anxiety Prospect from Worry States and Thought Control}

The belief the interviewee has on worry $(B w)$ as a strategy for taking attention away from the interview threat is capable of manifesting into more worries 
and this further affects the control of thoughts. The lack of thought control (Tc) degrades the positive self-appraisal state and this can throw the interviewee off balance as anxiety builds (Hirsch \& Mathews, 2012). Conversely, thought control can be enhanced by positive personal appraisal $(A p)$ as worry over time (anxiety) $(L w)$ reduces it.

Short-term worry $(S w)$ manifests due to the aggregated impact of the states of belief about worry $(B w)$, threat $(\mathrm{Th})$, coping resources $(\mathrm{Cr})$ and selfappraisal $(A p)$. These four constructs can be grouped into two parts, escalating and de-escalating parts. The proportional aggregate of belief about worry and threat is related to the escalating part while coping resources and positive selfappraisal are related to the de-escalating part (Gong et al., 2016; Ryum et al., 2017).

From Equations (5) to (7), the effect of belief about worry $(B w)$ is dependent on low and high values from task-specific threat $(T h)$, sensitivity $(S y)$ and long-term experienced worry $(L w)$. Short-term experienced worry $(S w)$ is positively impacted by the high level of threat $(T h)$, belief about worry $(B w)$, low level coping resources $(C r)$, and low level positive appraisal $(A p)$. Thought control $(T C)$ is causally increased by positive self-evaluation (appraisal) whereas long-term experienced worry $(L w)$ decreases its effects.

$$
\begin{aligned}
& B w(t)=\gamma_{b w} \cdot\left(\beta_{b w} \cdot \operatorname{Th}(t)+\left(1-\beta_{b w}\right) \cdot L w(t)\right)+\left(1-\gamma_{b w}\right) \cdot S y(t) \\
& S w(t)=\left(\varphi_{s w} \cdot B w(t)+\left(1-\varphi_{s w}\right) \cdot \operatorname{Th}(t)\right) *\left(1-\left(\begin{array}{c}
\psi_{s w} \cdot \operatorname{Cr}(t) \\
+\left(1-\psi_{s w}\right) \cdot A p(t)
\end{array}\right)\right) \\
& T c(t)=A p(t) \cdot(1-L w(t))
\end{aligned}
$$

\section{Temporal Relationships}

The formation of appraisal $(A p)$ in Equation 8 is modeled using the contributions of belief about worry $(B w)$, coping resources $(C s)$, and thought control $(T c)$ which accumulate with time. Meta-worry, which can contextually be defined as long-term experienced worry $(L w)$, is the accumulation of exposure of short-term worry $(S w)$ over time as shown in Equation 9.

$$
A p(t+\delta \mathrm{t})=A p(t)+\beta_{a p} \cdot((Z x(t)-A p(t)) \cdot(1-A p(t)) \cdot A p(t)) \cdot \delta \mathrm{t}
$$

where

$$
\begin{array}{r}
Z x(t)=\left(\omega_{z x} \cdot \operatorname{Cr}(t)+\left(1-\omega_{z x}\right) \cdot T c(t)\right) \cdot(1-B w(t)) \cdot(1-S y(t)) \\
L w(t+\delta t)=L w(t)+\alpha_{l w} \cdot((S w(t)-L w(t)) \cdot(1-L w(t)) \cdot L w(t)) \cdot \delta \mathrm{t}
\end{array}
$$




\section{Simulation Results}

This section presents results for two extreme cases for fictional interviewees studied during interview tasks. These cases were: 1) a highly anxious interviewee, and 2) a non-anxious interviewee. The designed agent models were executed using a numerical programming platform to simulate a large number of conditions of fictional individuals. Some interesting patterns were obtained with variations in these conditions. Several parameters were varied to simulate different characteristics. However, in this study, the duration of the simulation was fixed at 500-time steps $\left(t_{\max }=500\right)$ to simulate an interview session. This simulation time represented the regulated time set for an interview. Therefore, it meant that for an average interview session of 2 hours, each second of the interview represented approximately four time steps of the simulation traces.

The static parameters and weight values for the model were $\Delta t=0.2$,

$\omega_{c r 1}=\omega_{c r 2}=\omega_{c r 3}=\omega_{c r 4}=0.25, \alpha_{s y}=\beta_{p r}=\psi_{s w}=\alpha_{c r}=\beta_{a p}=\alpha_{l w}$

$=\omega_{z x}=0.5, \varphi_{s w}=0.7$, and $\gamma_{b w}=0$.

The parameter settings were selected such that the exhibited patterns were related to known behaviours of the constructs in the domain literature. The values of the static parameters were merely to tune the behaviour of the model to an expected degree based on the simulation experiments. Values were allocated to the weight of each factor based on their identified strength of contribution in the literature. The parameters were estimated by changing their values based on several runs of the simulation. This allows for the determination of the most suitable parameter values for the model as consequences to be matched with the literature. Table 2 provides the initial values for all exogenous factors for each fictional interviewee.

Table 2

Values of the Input Factors for Two Extreme Scenarios

\begin{tabular}{lcc}
\hline Input factors & Interviewee \#1 & Interviewee \#2 \\
\hline Relatedness (Rd) & 0.1 & 0.9 \\
Task demand (Td) & 0.9 & 0.1 \\
Self-efficacy (Se) & 0.1 & 0.9 \\
Prior experience (Pe) & 0.1 & 0.9 \\
Personal autonomy (Pa) & 0.1 & 0.9 \\
Social support (Ss) & 0.1 & 0.9 \\
Trait anxiety (Tr) & 0.9 & 0.1 \\
Personality (Pn) & 0.1 & 0.9 \\
\hline
\end{tabular}


The simulation process begins with the initial values to execute the cyclic relations. During the experiments, all conditions were bounded within $0^{3} x(t){ }^{3} 1$, and the iteration continued until several equilibria points were achieved (Treur, 2016b; Vancouver \& Weinhardt, 2012). In this article, the input parameters were assigned as high at 0.9 and as low at 0.1 (as shown in Table 2). These values were meant to test whether the simulation results of the fictional interviewee with extreme anxiety cases conformed to expectations in the literature.

\section{Simulation Cases}

A number of cases were simulated to arrive at certain conclusions. However, two cases of anxious and non-anxious interviewees are presented in this article. These cases were obtained from several psychological domains and previous experiments such as in Aziz et al. (2016), Borkovec et al. (2004), and Wells (2005).

Scenario 1: This scenario was intended to simulate conditions when a vulnerable interviewee was confronted with an unfavourable interview process. The vulnerability constructs were defined through a set of low experience, self-efficacy and assertiveness. The simulation results are shown in Figure 2.

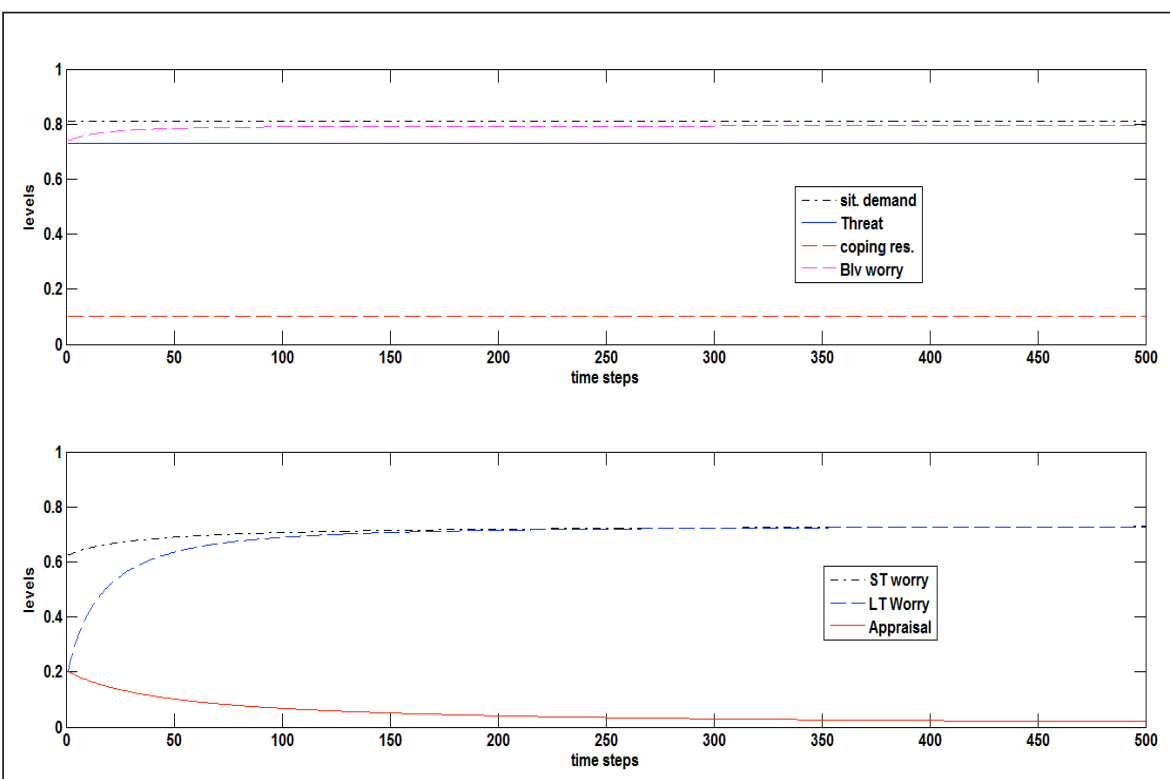

Figure 2. Simulation Results for a Vulnerable Interviewee. 
Figure 2 shows the visualized results for Scenario \#1. Overall, the results showed the dramatic change of anxiety level correspondent to the experienced situational demands. As the appraisal level was low through the simulation intervals, both short-term and long-term worries were spiked up. These results could be reflected through the formation of several instantaneous constructs such as high levels in belief about worry and perceived threat. This is consistent with underlying findings in theories where belief about worry (negative) is inversely proportional to the formation of appraisal (positive). In addition, belief about worry has a direct proportional rate with the formation of both short-term and long-term worries. From the theories, these effects are derived from the manifestation of meta-cognitive worry which has the capability to diminish individuals' capabilities to regulate their thought control (Borkovec et al., 2004).

Scenario 2: This scenario provides the simulation results of an individual with lesser risk factors in anxiety. In this scenario, the exogenous variables were initialized with high levels of assertiveness, social support and experiences in previous interviews. Moreover, prior experiences could be obtained from training programmes as one of the potential implementations of this model.

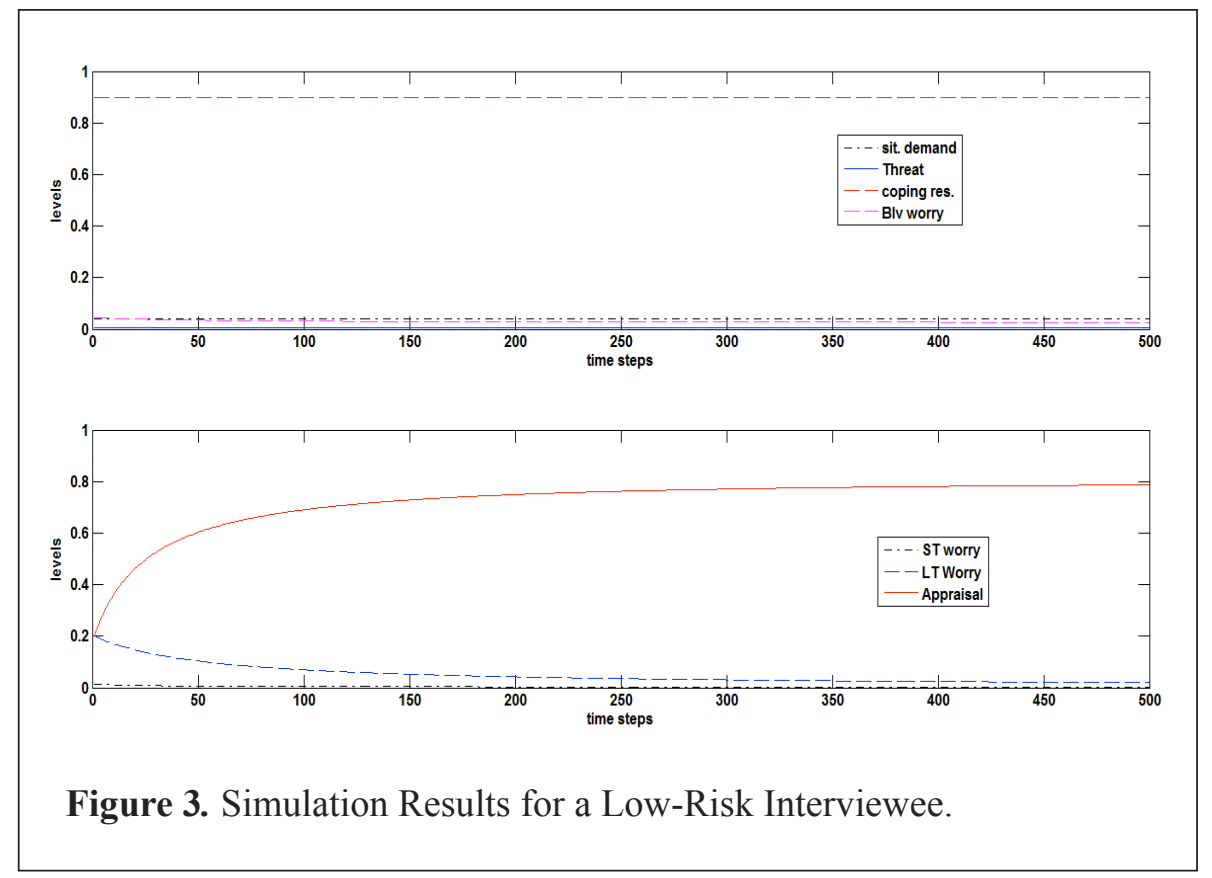

The simulation results from Figure 3 showed that an individual with low-risk factors tended to regulate his/her belief about worry better than the 
high-risk individual. Thus, this individual would experience less worry due to the low trait in anxiety at the onset and experienced derived from high exposure to interviewing or selection process. The combination of the aforementioned constructs with a higher assertiveness level (positive personality) gives the individual a better advantage to overcome possible risks in developing worries despite heightened levels in situational demands and threats (Wells, 2005).

\section{MATHEMATICAL VERIFICATION}

The correctness of a model is generally the extent to which a model is free of design and development errors as well as its implementation conforming to its formal specifications. The verification process ensures that a correct model has been built. In this section, the possible equilibria points are analyzed. The important assumption, in this case, is that all external factors have constant (consistent) values and parameters are non-zero. The differential Equations 10 and 11 can be itemized from the temporal equations where an equilibrium state is characterized.

$$
\begin{aligned}
& d L w(t) / d t=\alpha_{l w}[S w-L w] \cdot(1-L w) \cdot L w \\
& d A p(t) / d t=\beta_{\mathrm{ao} \cdot}[Z x-A p] \cdot(1-A p) \cdot A p \\
& \text { where } \\
& \quad \mathrm{Zx}=(\mathrm{Cs}+\mathrm{Tc}) \cdot(1-\mathrm{Bw})
\end{aligned}
$$

Next, the equations are identified as,

$$
\begin{aligned}
& d L w(t) / d t=0 \\
& d A p(t) / d t=0
\end{aligned}
$$

Assuming all temporal parameters are equal to 1 , therefore these equations can be rewritten as,

$$
\begin{aligned}
& (S w=L w) \text { Ú }(L w=1) \text { Ú }(L w=0) \\
& (\mathrm{Zx}=A p) \text { Ú }(\mathrm{A} p=1) \text { Ú }(A p=0)
\end{aligned}
$$

Therefore, the first conclusion can be identified where the equilibria points can only occur when either $S w=L w$ or $L w=1$ or $L w=0$. The next step is to combine these three conditions into a new set of relationship, as in (A $\vee \mathrm{B} \vee$ C) $\wedge(D \vee E \vee F)$ expression.

$$
(S w=L w \vee L w=1 \vee L w=0) \wedge(\mathrm{Zx}=A p \vee \mathrm{A} p=1 \vee \mathrm{A} p=0)
$$


This expression can be elaborated using Distributive Law as $(\mathrm{A} \wedge \mathrm{D}) \vee(\mathrm{A} \wedge$ E) $\vee(A \wedge F) \vee, \ldots, \vee(C \wedge F)$ and this will result

$$
\begin{aligned}
& (S w=L w \wedge \mathrm{Zx}=A p) \vee(\mathrm{S} w=L w \wedge \mathrm{A} p=1) \vee(S w=L w \wedge \mathrm{Ap}=0) \vee \\
& (\mathrm{L} w=1 \wedge \mathrm{Zx}=A p) \vee, \ldots, \vee(\mathrm{L} w=0 \wedge \mathrm{Zx}=A p)
\end{aligned}
$$

These equations later provide possible combinations of equilibria points to be analysed further. In this article, only four important equilibria cases were selected to prove the stability of the model.

\section{Case \#1: $L w=0$}

In this case, both Equations 5 and 7 provide a set of equilibria points as in Equation 13 when;

$$
B w=\gamma_{b w} \cdot\left(\beta_{b w} \cdot T h\right)+\left(1-\gamma_{b w}\right) \cdot S y
$$

where all parameters and weights $=1$ then

$$
\begin{aligned}
& B w=T h+S y \\
& T c=A p \cdot(1-L w) \\
& T c=A p
\end{aligned}
$$

\section{Case \#2: $L w=1 \wedge A p=1$}

For this case, Equations 5, 6 and 7 provide a set of equilibria points through Equation 14 ;

$$
\begin{aligned}
& B w=\gamma_{b w} \cdot\left(\beta_{b w} \cdot T h+\left(1-\beta_{b w}\right)\right)+\left(1-\gamma_{b w}\right) . S y \\
& \text { If } \gamma_{b w}=1 \text { therefore; }
\end{aligned}
$$

$$
B w=\left(\beta_{b w} \cdot T h+\left(1-\beta_{b w}\right)\right)
$$

For Equation, it yields an equilibria point as in Equation 15;

$$
S w=\left(\varphi_{s w} \cdot B w+\left(1-\varphi_{s w}\right) \cdot T h\right) *\left(1-\left(\phi_{s w} \cdot C r+\left(1-\phi_{s w}\right)\right)\right)
$$

Where $\varphi_{s w}=0.5$ and $\psi_{s w}=0.5$

$$
\begin{aligned}
& \Rightarrow \mathrm{Sw}=0.5(\mathrm{Bw}+\mathrm{Th}) *(0.5(\mathrm{Cr}+0.5)) \\
& T c=A p \cdot(1-L w) \\
& \Rightarrow \mathrm{Tc}=0
\end{aligned}
$$


Case \#3: $S w=L w$

Consider Equation 5, the equilibria point is represented by Equation 16

$$
\mathrm{Bw}=\gamma_{b w} \cdot\left(\beta_{b w} \cdot T h+\left(1-\beta_{b w}\right) \cdot S w\right)+\left(1-\gamma_{b w}\right) \cdot S y
$$

\section{IMPLEMENTATION}

The verified model of interviewee anxiety can be integrated with the other two models (self-efficacy and motivation) to obtain a unified cognitive model of interviewee mental state. Consequently, the integrated cognitive agent model could be used as an underlying reasoning model to design an intelligent artefact that is capable of supporting interviewees with high-risk of anxiety. Therefore, the integrated cognitive model serves as an intelligent module of a computational framework for a human-aware system intended for an interview coaching domain. This type of system, known as an ambient intelligent system, can be developed by deploying the cognitive agent model as a reasoning engine. In this regard, more informed actions based on the reasoning engine in a knowledgeable manner which show more human-like behaviours in providing related support can be achieved (Treur, 2016a). Using this approach, this model could be encapsulated within existing virtual training agents to simulate the applicant's mental state in addition to other verbal and non-verbal behaviours which the systems are meant to realize.

\section{CONCLUSION}

This article presents a computational model of interview anxiety conceptualized from a theoretical framework of generalized anxiety disorder theories. The model was simulated based on several initial conditions to relate its dynamic properties with identified situations in the literature. Obtained simulation results adhered to known cases identified in the domain literature. For instance, the results showed that worry diminishes thought control (Borkovec et al., 2004), positive appraisal reduces negative beliefs about worry (Wells, 2005), and demanding situations increase task threat (Fonseca et al., 2014). The formalized anxiety model can be enhanced further through integration with other constructs (self-efficacy and motivation) in simulating an overall mental state of candidates during selection interviews. The understanding of human behavioural dynamics in a simulated interview environment using the technique of cognitive modelling provides a platform for innovative applications and solutions that contribute to an incisive understanding of intelligent systems. Therefore, the results can serve as a basis for building an intelligent virtual agent that provides support during interview training sessions. 


\section{ACKNOWLEDGEMENT}

This research received no specific grant from any funding agency in the public, commercial, or not-for-profit sectors.

\section{REFERENCES}

Ajoge, N. S., Aziz, A. A., \& Mohd Yusof, S. A. (2017). Formal analysis of self-efficacy in job interviewee's mental state model. Paper presented at the IOP Conference Series: Materials Science and Engineering. IOP Publishing Ltd. https://doi.org/10.1088/1757-899X/226/1/012118

Ajoge, N. S., Aziz, A. A., \& Mohd Yusof, S. A. (2017). On modeling of interviewee motivation mental states for an intelligent coaching agent. Paper presented at the The 10th Malaysian Software Engineering Conference.

Anderson, K., André, E., Baur, T., Bernardini, S., Chollet, M., Chryssafidou, E., ... Sabouret, N. (2013). The TARDIS framework: Intelligent virtual agents for social coaching in job interviews. In Lecture Notes in Computer Science (including subseries Lecture Notes in Artificial Intelligence and Lecture Notes in Bioinformatics) (Vol. 8253 LNCS, pp. 476-491).

Ayres, J., Keereetaweep, T., Chen, P., \& Edwards, P. A. (1998). Communication apprehension and employment interviews. Communication Education, $47(1), 1-17$.

Aziz, A. A., Ahmad, F., Yusof, N., Ahmad, F. K., \& Yusof, S. A. M. (2016). Formal analysis of temporal dynamics in anxiety states and traits for virtual patients. In AIP Conference Proceedings. https://doi. org/10.1063/1.4960841

Bakker, A. B., \& Demerouti, E. (2017). Job demands-resources theory: Taking stock and looking forward. Journal of Occupational Health Psychology. https://doi.org/10.1037/ocp0000056

Barrows, J., Dunn, S., \& Lloyd, C. A. (2013). Anxiety, self-efficacy, and college exam grades. Universal Journal of Educational Research. https://doi. org/10.13189/ujer.2013.010310

Berenbaum, H. (2010). An initiation-termination two-phase model of worrying. Clinical Psychology Review. https://doi.org/10.1016/j.cpr.2010.06.011

Borkovec, T. D., Alcaine, O. M., \& Behar, E. (2004). Avoidance theory of worry and generalized anxiety disorder. In Generalized anxiety disorder: \{Advances\} in research and practice.

Bosse, T., Memon, Z. A., \& Treur, J. (2011). A recursive BDI agent model for theory of mind and its applications. Applied Artificial Intelligence, $25(1), 1-44$. 
Chakraborti, T., Zhang, Y., Smith, D. E., \& Kambhampati, S. (2016). Planning with resource conflicts in human-robot cohabitation. Aamas 2016. https:// doi.org/10.1016/j.jmpt.2007.12.006

Cuncic, A. (2018). How can i be more assertive when i have social anxiety? Retrieved from https://www.verywellmind.com/how-can-i-be-moreassertive-when-i-have-social-anxiety-3024311

Derakshan, N., \& Eysenck, M. W. (2009). Anxiety, processing efficiency, and cognitive performance. European Psychologist, 14(2), 168-176. https:// doi.org/10.1027/1016-9040.14.2.168

Ekambareshwar, M., Mihrshahi, S., Wen, L. M., Taki, S., Bennett, G., Baur, L. A., \& Rissel, C. (2018). Facilitators and challenges in recruiting pregnant women to an infant obesity prevention programme delivered via telephone calls or text messages 11 Medical and Health Sciences 1117 Public Health and Health Services. Trials. https://doi.org/10.1186/ s13063-018-2871-5

Ellis, D. M., \& Hudson, J. L. (2010). The metacognitive model of generalized anxiety disorder in children and adolescents. Clin Child Fam Psychol Rev. https://doi.org/10.1007/s10567-010-0065-0

Eysenck, M. W., \& Calvo, M. G. (1992). Anxiety and performance: The processing efficiency theory. Cognition \& Emotion, 6(6), 409-434. https://doi.org/10.1080/02699939208409696

Feiler, A. R., \& Powell, D. M. (2015). Behavioral expression of job interview anxiety. Journal of Business and Psychology, 1-17.

Fernandes, L. E. R., Custodio, V., Alves, G. V., \& Fisher, M. (2017). A rational agent controlling an autonomous vehicle: Implementation and formal verification. Electronic Proceedings in Theoretical Computer Science. https://doi.org/10.4204/EPTCS.257.5

Fonseca, R., Blascovich, J., \& Garcia-Marques, T. (2014). Challenge and threat motivation: Effects on superficial and elaborative information processing. Frontiers in Psychology. https://doi.org/10.3389/fpsyg.2014.01170

Forbes, J. (2011). An examination of the relationship between positive psychological functioning and depression. Edith Cowan University. Retrieved from http://ro.ecu.edu.au/theses/412

Gong, L., Wen, L., Dajun, Z., \& Delef, H. R. (2016). Effects of emotion regulation strategies on anxiety during job interviews in Chinese college students. Anxiety, Stress, \& Coping, 29(3).

Hayes, S., Hirsch, C. R., Krebs, G., \& Mathews, A. (2010). The effects of modifying interpretation bias on worry in generalized anxiety disorder. Behaviour Research and Therapy, 48(3), 171-178. https://doi. org/10.1016/j.brat.2009.10.006

Heimberg, R. G., \& Keller, K. E. (1986). Cognitive assessment of socialevaluative anxiety in the job interview: Job interview self-statement schedule. Journal of Counseling. Retrieved from http://psycnet.apa.org/ journals/cou/33/2/190/ 
Heimberg, R. G., Madsen, C. H., Montgomery, D., \& Mcnabb, C. E. (1980). Behavioral treatments for heterosocial problems: Effects on daily selfmonitored and roleplayed interactions. Behavior Modification. https:// doi.org/10.1177/014544558042001

Hirsch, C. R., \& Mathews, A. (2012). A cognitive model of pathological worry. Behaviour Research and Therapy. https://doi.org/10.1016/j. brat.2012.06.007

Hoque, M., Matthieu, C., \& Martin, J. (2013). Mach: My automated conversation coach. Paper presented at the International Conference on Ubiquitous Computing (pp. 697-706).

Huffcutt, A. I., Van Iddekinge, C. H., \& Roth, P. L. (2011). Understanding applicant behavior in employment interviews: A theoretical model of interviewee performance. Human Resource Management Review, 21(4), 353-367.

Jeske, D., Shultz, K. S., \& Owen, S. (2018). Perceived interviewee anxiety and performance in telephone interviews. Evidence-Based HRM. https:// doi.org/10.1108/EBHRM-05-2018-0033

Khalid, H. M., Wei Shiung, L., Bin Sheng, V., \& Helander, M. G. (2018). Trust of virtual agent in multi actor interactions. ICAROB2018.

Kwon, J. H., Powell, J., \& Chalmers, A. (2013). How level of realism influences anxiety in virtual reality environments for a job interview. International Journal of Human Computer Studies, 71(10), 978-987.

Levy, A. R., Nicholls, A. R., \& Polman, R. C. J. (2011). Pre-competitive confidence, coping, and subjective performance in sport. Scandinavian Journal of Medicine and Science in Sports, 21(5), 721-729.

Lounsbury, J. W., Loveland, J. M., Sundstrom, E. D., Gibson, L. W., Drost, A. W., \& Hamrick, F. L. (2003). An investigation of personality traits in relation to career satisfaction. Journal of Career Assessment, 11(3), 287-307.

MacDorman, K. F., \& Entezari, S. O. (2015). Individual differences predict sensitivity to the uncanny valley. Interaction Studies. https://oi. org/10.1075/is.16.2.01mac

Matthew D, J., Melanie T., S., Sony, K.-P., \& Fugen, N. (2017). Anxiety disorders - the symptoms of anxiety. Retrieved from http://www. gracepointwellness.org/1-anxiety-disorders/article/38467-thesymptoms-of-anxiety

McCarthy, J., \& Goffin, R. (2004). Measuring job interview anxiety: Beyond weak knees and sweaty palms. Personnel Psychology, 57(3), 607-637.

Mohan, S., Venkatakrishnan, A., Bobrow, D., \& Pirolli, P. (2017). Health behavior coaching: A motivating domain for human-aware artificial intelligence research.

Narayanan, V., Zhang, Y., \& Kambhampati, S. (2015). A human factors analysis of proactive assistance in human-robot teaming. Paper presented at the 
IEEE/RSJ International Conference on Intelligent Robots and Systems (IROS).

Nunes, I., \& Luck, M. (2014). Softgoal-based plan selection in model-driven BDI agents. Proceedings of the 2014 International Conference on Autonomous Agents and Multi-Agent Systems.

Piniel, K., \& Csizer, K. (2015). Changes in motivation, anxiety and self-efficacy during the course of an academic writing seminar. In Motivational dynamics in language learning.

Piniel, K., \& Csizér, K. (2013). L2 motivation, anxiety and self-efficacy: The interrelationship of individual variables in the secondary school context. Studies in Second Language Learning and Teaching. https://doi.org/ http://dx.doi.org/10.14746/ssllt.2013.3.4.5

Rynes, S. L., Bretz, R. D., \& Gerhart, B. (1991). The Importance of Recruitment in Job Choice: A Different Way of Looking. Personnel Psychology. https://doi.org/10.1111/j.1744-6570.1991.tb02402.x

Ryum, T., Kennair, L. E. O., Hjemdal, O., Hagen, R., Halvorsen, J. Ø., \& Solem, S. (2017). Worry and metacognitions as predictors of anxiety symptoms: A prospective study. Frontiers in Psychology. https://doi. org/10.3389/fpsyg.2017.00924

Schunk, D. H. (1995). Self-efficacy, motivation, and performance. Journal of Applied Sports Psychology, 7(2), 112-137.

Schwartz, M. (2018). The relatonship between social anxiety and school motivation in sixth-grade students. Dissertation Abstracts International: Section B: The Sciences and Engineering.

Scivicque, C. (2013). Keeping Your Cool in a High Stress, High Stakes Interview. Retrieved from http://money.usnews.com/money/blogs/ outside-voices-careers/2013/09/19/how-to-keep-your-cool-in-a-highstress-interview

Soeter, M., \& Kindt, M. (2015). An abrupt transformation of phobic behavior after a post-retrieval amnesic agent. Biological Psychiatry. https://doi. org/10.1016/j.biopsych.2015.04.006

Spielberger, C., \& Vagg, P. (1995). Test anxiety: Theory, assessment, and treatment. Washington, DC: Taylor \& Francis.

Tahmassian, K., \& Moghadam, N. J. (2011). Relationship between self-efficacy and symptoms of anxiety, depression, worry and social avoidance in a normal sample of students. Iranian Journal of Psychiatry and Behavioral Sciences.

Tallis, F., Eysenck, M. W., \& Mathews, A. (1991). Worry: A critical analysis of some theoretical approaches. Anxiety Research.

Tan-Kristanto, S., \& Kiropoulos, L. A. (2015). Resilience, self-efficacy, coping styles and depressive and anxiety symptoms in those newly diagnosed with multiple sclerosis. Psychology, Health and Medicine. https://doi.or $\mathrm{g} / 10.1080 / 13548506.2014 .999810$ 
Treur, J. (2016a). Making Smart Applications Smarter. In Network-Oriented Modeling (pp. 463-471). Springer.

Treur, J. (2016b). Network-oriented modeling and its conceptual foundations. In Lecture Notes in Computer Science (including subseries Lecture Notes in Artificial Intelligence and Lecture Notes in Bioinformatics). https:// doi.org/10.1007/978-3-319-47874-6_12

Vancouver, J. B., \& Weinhardt, J. M. (2012). Modeling the mind and the milieu: Computational modeling for micro-level organizational researchers. Organizational Research Methods, 15(4), 602-623.

Wells, A. (1999). A cognitive model of generalized anxiety disorder. Behavior Modification. https://doi.org/10.1177/0145445599234002

Wells, A. (2005). The metacognitive model of GAD: Assessment of metaworry and relationship with DSM-IV generalized anxiety disorder. Cognitive Therapy and Research. https://doi.org/10.1007/s10608-0051652-0

Zakershahrak, M., Sonawane, A., Gong, Z., \& Zhang, Y. (2018). Interactive plan explicability in human-robot teaming. https://doi.org/10.1109/ ROMAN.2018.8525540 